\title{
The Role of Visualization in Mathematics and its Implementation in Nomotex DLS
}

\author{
Yury I. Dimitrienko ${ }^{1}$, Kirill M. Zubarev ${ }^{1 *}$, Elena A. Gubareva ${ }^{1}$, Sergei V. Sborshikov ${ }^{1}$, and \\ Raisa K. Alesina ${ }^{1}$ \\ ${ }^{1}$ Bauman Moscow State Technical University, 2nd Baumanskaya str., 5/1, 105005, Moscow, Russia
}

\begin{abstract}
In this paper, visualizations of second-order curves are considered, created in the Digital Learning System (DLS) Nomotex. Engineering and mathematical examples related to these concepts are given. The visualization collection created on the basis of the Nomotex platform is used for training engineers at the Bauman Moscow State Technical University. Engineering examples help students better understand the essence of mathematical concepts, as well as learn where this section of mathematics is applied. The paper provides mathematical and engineering examples on this topic, in particular, various images of an ellipse and its properties are given, an elliptical reflector is demonstrated. The article discusses the feasibility of using engineering examples for a particular specialty. The paper compares the performance of students using the Nomotex platform and students studying in the traditional way. The authors estimate the time required to create such visualizations. The authors note the expediency of creating a collection of visual mathematics, which would contain similar visualizations for all mathematical concepts. All examples are implemented using Phyton language facilities.
\end{abstract}

\section{Introduction}

The Digital Learning System (DLS) Nomotex is a new technology aimed at increasing the level of mathematical training of students enrolled in the main areas of training for engineers at the "bachelor's" level, and the technology is also aimed at reducing the time spent on training.

To intensify the process of mastering the mathematical knowledge of an engineer and the development of cognitive abilities, a cognitive-visual technology for teaching mathematical disciplines has been developed, which is aimed at developing students' skills in scientific research, scientific organization of educational work, scientific observation of phenomena, collection of scientific data, and their subsequent visual fixation.

The implementation of cognitive-visual technology is carried out through the development of problem-oriented visual images of the content of mathematical knowledge.

The discipline "Analytical geometry" is included in the basic section of mathematical disciplines. It is studied in almost all technical universities and in all classical universities [1-6]. The discipline is usually studied in the 1st semester of the 1st year. For its study,

* Corresponding author: zubarevkm@bmstu.ru 
additional knowledge is not required from higher mathematics, which makes it attractive for processing using a new mathematical technology, which is being developed in the project to create the Nomotex platform [5].

An additional important factor is that the subject matter of the discipline is based on geometric concepts - vectors, planes, surfaces, etc., which can be effectively implemented by means of computer animation [1] and will contribute to the attractiveness of the created technology for the student audience.

Second Order Curves is one of the topics covered in the Analytical Geometry course. This section deals with curves defined by the following equation:

$$
\begin{gathered}
a_{11} x^{2}+2 a_{12} x y+a_{22} y^{2}+2 b_{1} x+2 b_{2} y+c=0 \\
a_{11}^{2}+a_{12}^{2}+a_{22}^{2} \neq 0
\end{gathered}
$$

The mathematical examples considered in this paper are implemented on the basis of the DLS Nomotex educational information environment [1-5], created at the Bauman Moscow State Technical University at the Department of Computational Mathematics and Mathematical Physics. The Nomotex platform was created for classroom training of engineers and, in fact, is a knowledge base for all mathematical disciplines. Each mathematical concept is complemented by a unique visualization. The entire knowledge base is available to students and for home study [6]. The platform is also used to carry out control activities: tests are used to test the knowledge of the theory, to test practical skills (problem solving), tasks with the input of the answer are used [7-11].

Why are mathematical examples created? They replace the familiar illustrations that the teacher draws on the board. The advantage of visualizations is that they are more accurate, presented in three-dimensional space, and significantly save time in classroom sessions $[12,13]$.

\section{Second-order curve visualizations}

In the course of analytical geometry, students are offered to study curves of three types: elliptic, hyperbolic, parabolic. The program on this topic includes the problems of constructing displaced curves of the second order, finding various characteristics of curves of the second order, constructing tangents to curves of the second order, studying the optical properties of curves of the second order [14, 15].

For each curve type, unique visualizations have been created to help you better understand the concepts of second-order curves, and to demonstrate the characteristics and properties of the curves. Such mathematical examples greatly simplify the presentation and perception of the material. Figure 1 shows a $2 \mathrm{D}$ rendering of an ellipse. 


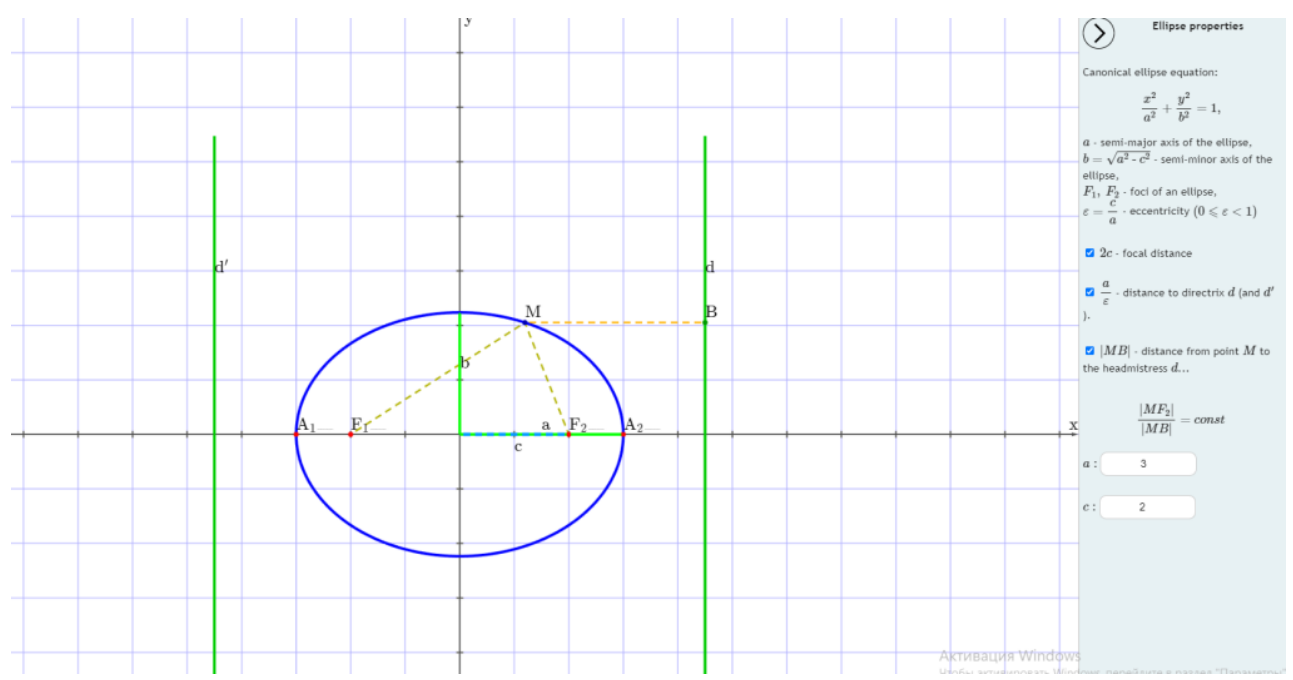

Fig. 1. 2D rendering of an ellipse.

This example is not static, students and teachers have the ability to change various parameters of the ellipse, for example, you can increase or decrease the size of the semiaxes of the ellipse automatically, and the position of the foci and directrix changes automatically. You can also, on the contrary, change the position of the focuses or directrixes, and the ellipse itself will change $[17,18]$. This example allows you to visually demonstrate the properties of an ellipse, see how an ellipse looks like with various parameters. Figure 2 shows the visualization of a tangent to an ellipse [19].

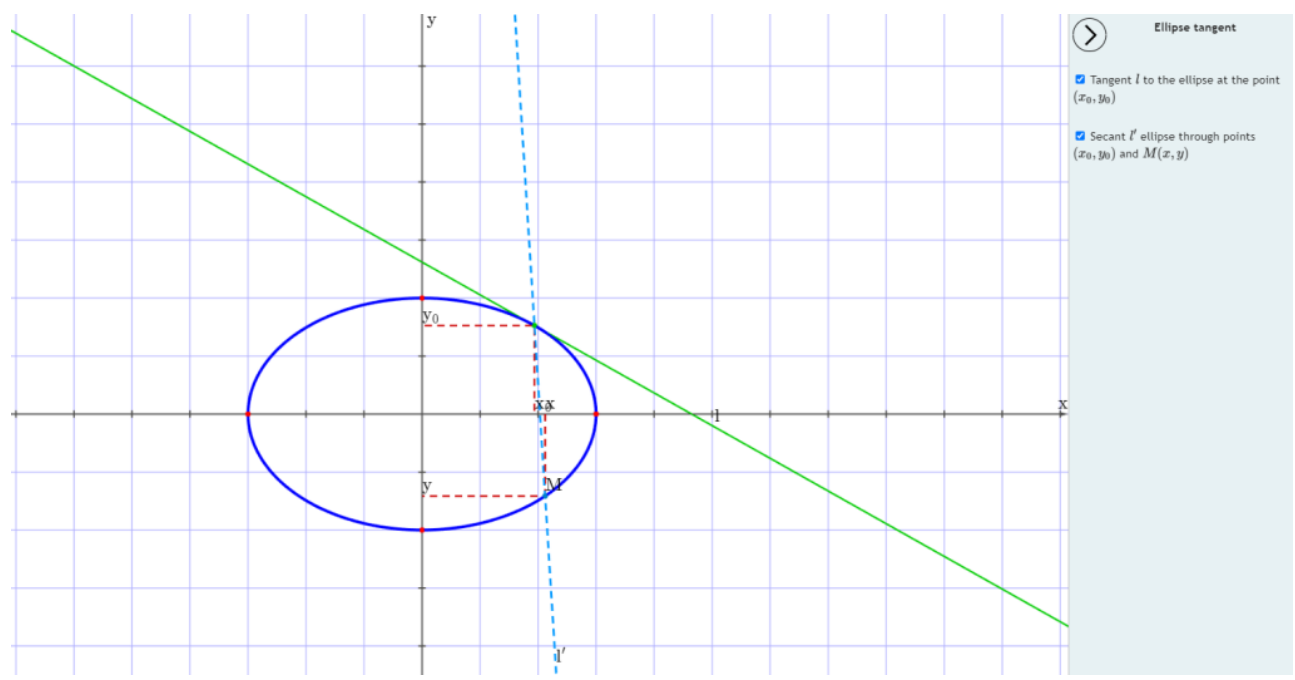

Fig. 2. 2D visualization of a tangent to an ellipse.

This picture is also not static, the user has the ability to change the size of the ellipse, and also watch how the tangent will pass at any point of the ellipse. Also, this visualization allows you to build a secant ellipse passing through any 2 points [20].

Similar visualizations were created for other curves of the second order. Figure 2 shows the visualization of the hyperbola and its numerical characteristics. The analytical geometry course using the DLS Nomotex environment allows you to accommodate more 
mathematical concepts than the traditional course, since during the lecture the teacher saves time on displaying second-order curves.

\section{Engineering examples on the topic of second-order curves}

Of particular interest are engineering examples that help to understand where the concept of second-order curves is applied in practice, and what their properties are for [20, 21, 22].

One of the most important properties of an ellipse is its optical property: the focal radii of an arbitrary point $M_{0}$ of the ellipse form equal angles with the tangent to the ellipse at this point. As an engineering example for this property, a three-dimensional visualization of an elliptical reflector [23] in solid-state lasers was created, Figure 3.

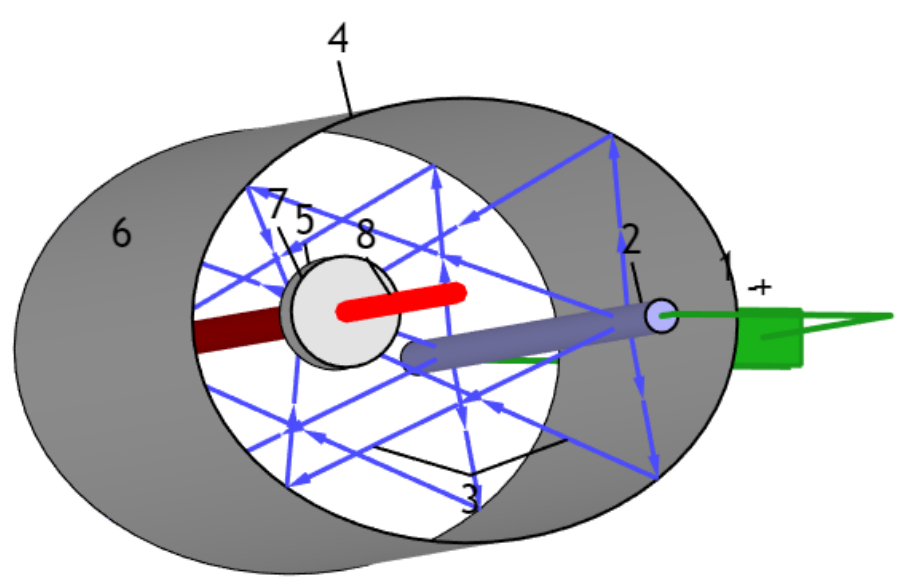

Fig. 3. Elliptical reflector in a solid state laser.

A cylindrical flash lamp is located at one of the focuses $F_{1}$ of the reflector, which has an elliptical cross-section [7]. According to the optical property of the ellipse, the reflected rays are collected in the second focus $F_{2}$. Since the sum of the focal radii, $r_{1}+r_{2}$ which are the lengths of the direct and reflected beams, in the ellipse will be the same for all beams diverging in different directions from the flash lamp, all these beams will be collected at the same time. In the second focus $F_{2}$ there is an active element 5 , for example, ruby. Focused light beams generate laser (monochromatic, unidirectional) radiation in the active element, which is repeatedly reflected and amplified from an optical resonator consisting of an opaque (6) and semitransparent mirror (7). Having been amplified many times in the optical resonator, the radiation through the semitransparent mirror is released outside - a thin laser beam (8) with a very small divergence angle is formed, coherent (oscillation in one phase), monochromatic (oscillation at one frequency) $[7,8,9,10]$.

The user has the ability to remove or add any of the laser elements, and even turn on the laser itself. 


\section{Conclusions}

In the work, visualizations of mathematical concepts on the topic of second-order curves were described, and engineering examples were presented that demonstrate the application of the optical properties of a hyperbola and an ellipse. Of particular interest are engineering examples that allow us to understand the practical importance of the studied mathematical concepts. A further goal of the authors is to create engineering examples that would show the practical importance for each of the specialties.

\section{References}

1. Ya.I. Kuzminov, M. Carnoy, Panel discussion, Online Learning: How It Affects the University Structure and Economics, Voprosy obrazovaniya, No. 3, pp. 8-43 (2015)

2. V. Gromyko, V. Kazaryan, N. Vasilyev, A. Simakin, S. Anosov, Artificial intelligence as tutoring partner for human intellect, Advances in intelligent systems and computing, № 658, pp. 238-247 (2018)

3. V. Mayorova, O. Zhdanovich, Innovative collaborative educational programs for space systems engineers, Proceedings of the International Astronautical Congress, IAC (2016)

4. G. Procurat, A. Strukova, A. Vukolov, O. Egorova, Generated graphics and game development software in engineering education: Perspectives and experience of usage, Mechanisms and Machine Science, № 64, pp. 123-130 (2019)

5. N. Serdyukova, V. Serdyukov, S. Neustroev, Testing as a feedback in a smart university and as a component of the identification of smart systems, Smart Innovation, Systems and Technologies, № 144, pp. 527-538 (2019)

6. V. Guznenkov, P. Zhurbenko, The Academic Discipline 'Computer Graphics' for the Open Education System, 2018 4th International Conference on Information Technologies in Engineering Education, Inforino 2018 - Proceedings 8581738 (2018)

7. A. Karpov, Education for knowledge society: Learning and scientific innovation environment, Journal of Social Studies Education Research, № 8(3), pp. 201-214 (2017)

8. K.F. Deborah, Practices for Student Success: From Face-to-Face to At-Scale and Back, No. 4, pp. 116-138 (2018)

9. Yu. Dimitrienko, E. Gubareva, New technology of mathematical training of engineering personnel, based on a neural network model of knowledge, Innovation in education, № 11, pp. 129-140 (2017)

10. Yu. Dimitrienko, E. Gubareva, K. Zubarev, S. Kudryavtseva, Methodological support of the continuing education of teachers on the development of online courses at bmstu, Science diary, № 11 (2018)

11. Yu. Dimitrienko, E. Gubareva, Hierarchical neural network model for mathematical knowledge and software NOMOTEX for mathematical training of engineers, IOP Journal of Physics: Conference Series, volume 1141012010 doi:10.1088/17426596/1141/1/012010 (2018)

12. Yu. Dimitrienko, E. Gubareva, T. Oblakova, Methodology for assessing knowledge on the course "Mathematical Analysis" in the digital environment NOMOTEX, Innovative development, № 9, pp. 8-11 (2018)

13. M. Janelli, E-Learning in Theory, Practice, and Research, No. 4, pp. $81-98$ (2018) 
14. I. Horváth, Innovative engineering education in the cooperative VR environment, 7 th IEEE International Conference on Cognitive Infocommunications (CogInfoCom), pp. 359-364 (2016)

15. C.Y. Chao, Y.T. Chen, K.Y. Chuang, Exploring students' learning attitude and achievement in flipped learning supported computer aided design curriculum: A study in high school engineering education, Computer Applications in Engineering Education, 23(4), pp. 514-526 (2015)

16. J. Gutierrez, C.E. Mora, B. Anorbe-Diaz, A. Gonzalez-Marrero, Virtual Technologies Trends in Education, Eurasia Journal of Mathematics, Science and Technology Education, 13(2), pp. 469-486 (2017)

17. A.P. Markopoulos, A. Fragkou, P.D. Kasidiaris \& J.P. Davim, Gamification in engineering education and professional training, International Journal of Mechanical Engineering Education, 43 (2), pp. 118-131 (2015)

18. S. Junk, R. Matt, Workshop Rapid Prototyping - a new approach to introduce Digital Manufacturing, engineering education Proceedings of 14th International Conference on Information Technology Based Higher Education and Training, ITHET, IEEE Xplore, Lisbon, Portugal, pp. 1-6 (2015)

19. M.L. Florence, D. Swamydoss, New revolution in education-digital classroom, Online Journal of Distance Education and e-Learning, № 5 (1), pp. 66 (2017)

20. M. Leary, M. Mazur, M. McMillan, M. Brandt, A. Subic, [DesktopLabs] Desktop Laboratories: Web Share and Additive Manufacture of Engineering Educational Models Procedia Technology, Vol. 20, pp. 111-116 (2015)

21. V. Potkonjak, M. Gardner, V. Callaghan, P. Mattila, Ch. Guetl, V. Petrović, K. Jovanovic, Virtual Laboratories for Education in Science, Technology, and Engineering: a Review, Computers \& Education, Vol. 95, pp. 309-327 (2016)

22. B. Gan, T. Menkhoff, R. Smith Smith, Enhancing students' learning process through interactive digital media: New opportunities for collaborative learning, Computers in Human Behavior, Vol. 51, Part B, October 2015, pp. 652-663 (2015)

23. L. Braghirolli, J. L. Ribeiro, A. Weise, M. Pizzolato, Benefits of educational games as an introductory activity in industrial engineering education, Computers in Human Behavior, No. 58, pp. 315-324 (2016) 